\title{
Early clinical exposure- Why and how?
}

\author{
Chinmay Shah \\ Associate Professor, Department of Physiology, Government Medical College, Bhavnagar, Gujarat
}

Corresponding Author:

Email: cjshah79@yahoo.co.in

A revolution in medical education arose in the 20th century and soon led to the establishment of what we may call a "Hopkins Circle." The result was the release of the famous "Flexner Report" also called as "the Carnegie Foundation Bulletin Number Four" in 1910. Aside from other guidelines, the report laid down the foundation of what we are still implementing today (a century later) - "the pedagogic pattern of training in medical schools." The distinctive feature of this report is the two years exclusive training on basic sciences (preclinical) followed by 2 years of clinical (patient) exposure. Clearly, the preclinical or the basic training has been siloed from the clinical training in this traditional format. This pattern was needed at that time, and much good came by implementing the same. ${ }^{1}$

However, 21st century conceptions of professionalism are much broader. ${ }^{2}$ Doctors must communicate well, respect their patients' wishes and needs, and be accountable to society. In their education, "insufficient weight has been given to the ethical, attitudinal, and interpersonal features of medical practice." "3 Modern medical education must therefore lay affective and social as well as scientific foundations. ${ }^{4-6}$ At the same time, Flexner's preclinical to clinical sequence is being challenged by early clinical exposure. $^{7-9}$

Thus the problem is "Physicians of tomorrow are taught by teachers of today using curricula of yesterday."

The rapid pace of change in health care and medicine is giving rise to corresponding rapid changes in the content and process of medical education around Globe.

As director of the Kellogg Foundation Dr. T. A. Bruce recently proposed, "perhaps it isn't so much the content of our educational programmes that is remiss, but the context in which they are carried out." 10

In 1993, the UK's General Medical Council's (GMC) tomorrow's doctor advocated introducing students to clinical medicine early in their studies, using real clinical situations to make teaching more practical, relevant, stimulating, and reinforcing the vertical integration between the basic medical and clinical sciences ${ }^{11}$ In 1998 a position paper from the World Federation of Medical Education (WFME) clearly recommended that "medical education must to the greatest possible extent integrate basic and clinical disciplines with a focus on key principles. Students should meet patients early on." 12 The Health Professions
Council of South Africa (HPCSA), the professional body responsible for accrediting medical and dental Faculties, recommends early clinical contact during the basic study years to contribute to enthusiasm and communication skills development. ${ }^{13}$

Early clinical exposure also addresses other concerns of WFME. The emphasis of medicine needs to be on generalist (rather than specialist) training, with the graduates having experiences in a variety of settings (hospitals, communities, primary health care, amongst others). ${ }^{12}$

After a century of Flexner's landmark study, a summary of Educating Physicians," by "Molly Cooke, David M. Irby, and Bridget C. O'Brien" recommended ${ }^{1}$ following guidelines: At every level, the approaches to teaching must emphasize that "competence means minimal standard" of level of performance that all aspiring physicians must attain The report called for "high intensity of integrated knowledge and skill in early patient experience," i.e. vertical integration of "practical experiences" in to early traditionally theory years. ${ }^{1}$

Many country have already started implementing ECE i.e. Europe, ECE was implemented in 32 of the 40 medical schools, ${ }^{14}$ Indonesia, ECE during the preclinical years reduced difficulties commonly encountered by students during clinical year. ${ }^{15}$ Nepal, ECE is offered to first and second year undergraduate medical students who follow an integrated, organ system-based curriculum and student feedback about ECE has been positive. $^{16}$

In India, Vision 2015 by Medical Council of India has recommended on several facets of medical education including ECE/experience in India albeit with a slight adaptation to our setup. ${ }^{17}$

Recommendations of UG group are: Foundation course, early clinical exposure, integration- vertical and horizontal, skill training/competency based training, electives, student doctor method of clinical training, secondary hospital exposure, newer teaching techniques - skill labs etc, community oriented education. In this paper we will discuss regarding early clinical exposure

\section{Definition}

Early Clinical exposure (ECE) is a teaching learning methodology, which fosters exposure of the medical students to the patients as early as the first year of medical college. ${ }^{18}$

In ECE students can play four types of roles: ${ }^{19}$ 
1. Passive Observer: As passive observers the students only observe a complicated situation such as performance of a trocar suprapubic cystostomy for urinary retention.

2. Active Observer: As active observers the students observe a simple situation such as performance of indwelling urethral catheterization in a female patient with urinary retention and also record their findings using a checklist.

3. Actor in Rehearsal: As actors in rehearsal the students perform a task for learning such as performance of indwelling urethral catheterization in a female pelvic simulator.

4. Actor in Performance: As actors in performance the students can assist a resident in performing an indwelling urethral catheterization in a female patient.

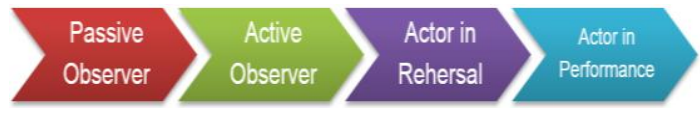

\section{The need for Early Clinical Exposure}

For generations, medical students have spent the preclinical years in classrooms and laboratories. In the traditional curricula of medical education, students learn theoretical knowledge without contact with the patient in a clinical context. Moreover, in clinical fields they cannot recall important basic science concepts; therefore, parts of their academic education becomes impractical. Traditionally, the foundation years of medical students have made them thorough in biomedical sciences but have hardly provided them with any clinical experience. ECE Act as bridge between preclinical disciplines and clinical disciplines.

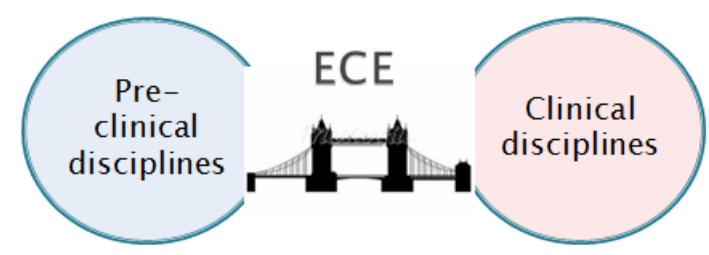

\section{Educational Theory Supporting ECE}

Irrespective of what form of ECE is chosen it provides a "spiral integrated model,"1 i.e., a consistently graduated clinical and preclinical exposure throughout the time a student is in medical college.

Incorporating Kolb's Learning Theory in ECE, ${ }^{20}$ promote active learning through self reflection and participating in case discussion. Students direct involvement in to learning processes develop their ability to possess and use analytical skills to conceptualise experience and to utilize their decision making skills when presented cases during their clinical practice as suggested by Lisco and O'Dell.
The goals of ECE are to provide significance to basic sciences along with expansion of medical knowledge so as to establish the cognitive component of professional learning. ${ }^{22}$ Concurrently, the students will develop some fundamental clinical skills as well as a moral attitude (to practice with integrity and respectability). All this will help the students to overcome their pressures and anxieties and motivate them to develop a better insight into the medical profession. ${ }^{23}$ It will also lead to a positive influence in the attitude of the student towards medical education which will help them to achieve social as well as professional satisfaction. ${ }^{24}$ As students face eternally growing amount of information in the medical sciences, ECE will increase their exposure to clinical problems and thus prepare them to be up-to-date physicians throughout their careers. ${ }^{25}$

Some of the advantages of early clinical exposure identified in the literature are that ECE forms a crucial part of initiation into medicine, smoothens the transition from layperson to student physician, provides an opportunity to bring social relevance and contextualize basic science learning, provides teaching and learning of basic clinical skills, enhances student motivation and encourages the students to learn professional behaviour. ${ }^{26}$ Students perception of advantages of ECE were that it provided important validation of the student's decision to go to medical school, it was a lifeline that helped the student stay focused on their studies and provided opportunity to establish a link between the basic sciences concepts and actual patient cases. ${ }^{26,27}$ Faculty perception of advantages of ECE were that it provided a more integrated approach to teaching basic sciences and clinical medicine, increased excitement for learning by students, provided better comprehension of basic science knowledge. ${ }^{26,27}$

\section{Implementation of ECE}

A few medical colleges in India have been using ECE in various ways to teach Physiology. ${ }^{28,29}$ Evaluation of these programs has shown that medical students appreciate them and it has enhanced their learning. However, the long-term impact of these programs is yet to be evaluated. ${ }^{28,39}$ Lets, see how they have implemented it.

We can implement ECE in three basic forms. ${ }^{23}$ College or a classroom setting wherein a patient (uncomplicated and cooperative) can be brought to the classroom and the basic science and clinical science teacher can discuss in detail with the students. In Hospital Settings Students can be taken to the hospital "wards/clinics" and made to understand the protocols and patterns. These two "patient encounters" can help the student enhance their skills and understand diseases and ailments. The third form of patient exposure is that of the "community or underserved opportunity program." Out of three setting, which setting is to be used is based on objective for which we want to use ECE. 
Objective $^{30}$ of ECE can be any of following:

It help students in improving Student's

a. Interest in Basic Science \& Integration of Basic and Clinical

b. Learning more interactive and student centred

c. Ability to build a Patient History and Physical Examination skills.

d. Comprehension of basic science knowledge as it relates to a patient's condition in the clinical setting.

e. Ability to identify critical information needs as they relate to a patient's condition in the clinical setting.

f. Ability to use problem-solving and critical thinking skills in a clinical application.

g. Ability to engage in self-directed learning

h. Leadership skills as they relate to an interdisciplinary team.

i. Communication and teaching skills peer-to-peer.

j. Communication and teaching skills with patients.

Each experience should be preceded by a preparation phase in which the students are informed about the objectives and type of experience. Each experience should be followed by a debriefing phase in which the students are encouraged to share their experiences, learning and other concerns about the experience. $^{32}$ Many instruments are available to document the clinical experiences and activities, including logbooks, computers, and encounter cards.

\section{Class room setting ${ }^{23}$}

In a typical Physiology classroom, ECE can be used as an educational strategy either by bringing patients to the classroom or through case discussions. It can be done in multiple small groups of students instead of a single large class if enough space, time and faculty members are available. Paper cases, Photographs, X-rays, Laboratory reports, ECG With or without Clinical Teacher.

a. A patient with hyperthyroidism can be brought into the Physiology classroom after appropriate consent has been taken.

b. Alternatively if the clinician is not available, the Physiology teacher can himself/ herself take the class as described above. It is important though, that the Physiology teacher should have discussed the clinical signs and symptoms with the clinician prior to the class.

c. If a patient cannot be brought to the class room a paper based case on hyperthyroidism can be used as a trigger for discussion. However, this is an alternative only because of feasibility issues and does not comply with the definition of early clinical exposure which states that "it is an authentic human contact in a social or clinical context that enhances learning of health, illness or disease, and the role of the health professional"

We can use any of variant of class room settings like Case-stimulated learning, Patient-centred learning curriculum or Problem-based learning within lectures.

\section{Hospital settings ${ }^{23}$}

Students in small groups are taken to the hospital either to the wards or outpatient block. The physiological concepts are discussed by the clinician in the context of the patients seen.$^{23}$ Case can be of cardiovascular system i.e MR/MS/CHF, Endocrine system: Hyper-hypo thyroid, Respiratory System, Anaemia, Jaundice.

The learning objectives need to be stated clearly. In addition observation guides are to be developed by the Physiology and clinical faculty so that the student knows who to observe, what to observe and what to report back. $^{31}$

Observation guides help to structure observations made by the students in a clinical setting, an active purposeful task that stimulates deep learning. ECE in hospital setting will:

1. Familiarise them with a clinical environment

2. Create awareness in them different presentation of cases

3. Observe doctor patient relationship

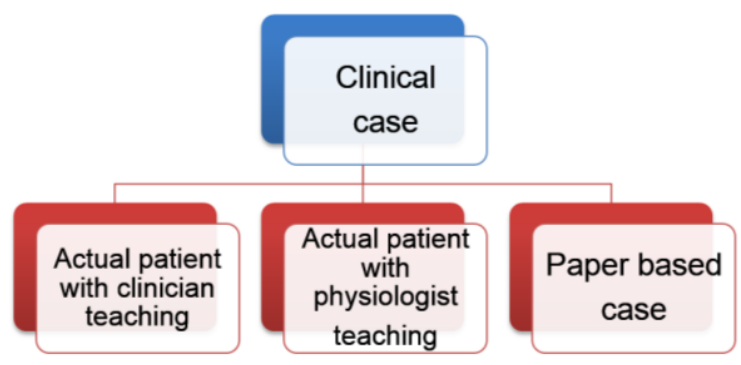

\section{Community settings}

The focus of community based early clinical exposure should be on providing the context for basic science learning; integration of basic sciences, clinical dimensions and societal perspectives; seeing primary care providers at work and student involvement through activities. $^{24}$

Student learn about how people live, how their living condition affect influence health and disease, Responsibility of doctor and other health professional. i.e. The first year medical students spend a week in small hospitals of their choice in rural areas. They had a structured program where they learned basic science concepts through the clinical Material available there. The students can pick up cases which were treated and had a discussion on the basic science concepts.

This will help us to inculcate:

a. Behavioural and social sciences and ethical dimensions of patient - doctor relationship.

b. Help to learn preventive aspects of Medicine.

c. This helped to bring in the socio-clinical relevance and context to the students'.

Multiple-format sessions for teaching physiology ${ }^{33}$ : A didactic lecture, a whole class discussion session, a quiz, and a patient presentation". Two Days: This method allowed students to listen, read, discuss and solve 
problems in a large group format. This format was based on the key concept that repetition facilitates learning.

What are crucial to the success of the ECE program

It would be explicitly stated specific learning objectives, development of appropriate cases for classroom setting, observation guides for hospital setting and designing relevant and feasible projects for community setting.

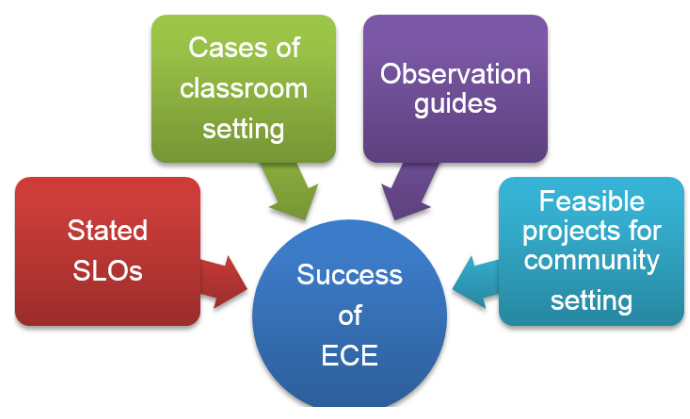

ECE will not only affect Students behaviour, learning in all three domain, carrier choice but also affect their Professional roles and relationships. It has multi dimensional effect like.......

\section{Effects on teachers ${ }^{34}$}

Primary care teachers in medical school will be motivated to supervise students' early experience by their enjoyment of teaching and a wish to "give something back to the profession". Effects on populations: A field exercise in which students were first trained to measure blood pressure, then measured the blood pressure of a population will be of potential benefit to the population involved; medical students from the same school have delivered oral health, detected and treated trachoma, and helped manage malnutrition. ${ }^{35}$ Effects on individual patients: Qualitative analysis of patients who had been interviewed by first year medical students found the patients satisfied for several reasons; the interviews were satisfying, they had favourable impressions of the students, and were please to contribute to their education. ${ }^{36}$

Success of any implemented programme is largely depends on program Evaluation and Assessment: Program evaluations and student assessments are important "because we want to know the value of the activity into which we have invested time, energy, and other resources." ${ }^{\prime 37}$ The evaluations can guide future decisions by determining effectiveness, optimizing resources, identify areas for improvement, and determining how best to utilize individuals in their respective roles. ${ }^{37}$ In addition, assessment of the students is beneficial because it enables the educators to determine how well the students are doing. ${ }^{37}$

Short-term Evaluation can be done in the form of Survey of student and faculty, Reflection of student experience, improvement in student understanding can be assessed using Clinical Experience Questionnaire, formative exams, Facilitator Assessment and also using Peer Assessment.

Long-term Evaluation \& Assessment can be done using comparing result of class with and without ECE, or using OSPE/OSCE for assessment of clinical skill.

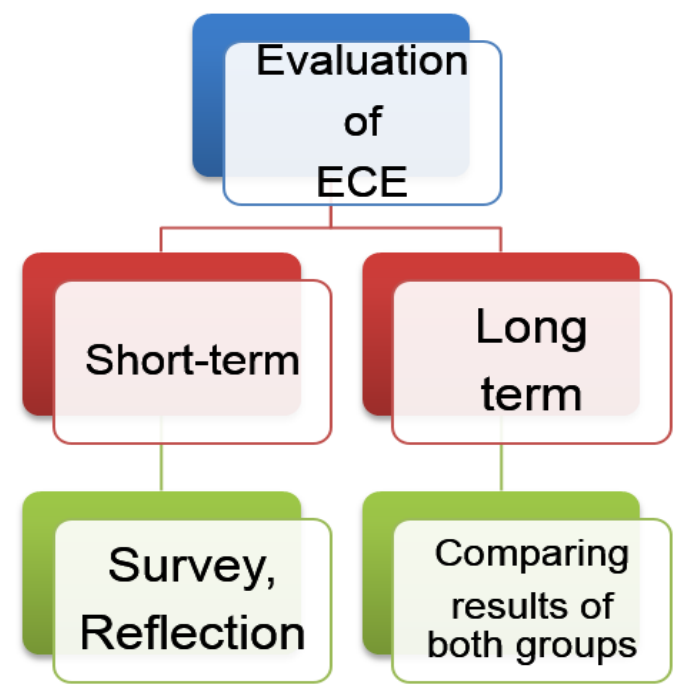

\section{Problems Encountered in ECE}

It will not be easy to implement ECE, ECE is a time consuming method and cannot be applied to each topic. Some students who are academically weak find it difficult to live up to the expectations of an ECE module. Another challenge that can be encountered during ECE are identifying and coordinating with supportive clinical departments and cooperative patients. ${ }^{38}$

To increase its efficacy, there should be a hybrid method, whereby the entire syllabus is not covered, but ECE is used only for a few important and commonconditions. ${ }^{39}$ ECE consumes more manpower, infrastructure and extra efforts on the part of the faculty which is another drawback.

Identifying clinically relevant core content and framing its learning objectives is also a challenge for the faculty and may require training before being executed Identifying clinically relevant core content and framing its learning objectives is also a challenge for the faculty and may require training before beingexecuted. ${ }^{40}$ Sometimes ECE can create confusion in the minds of the student, because a disease can effect multiple systems at the cellular level, so to study about any disease not only is anatomy and physiology essential but also the pathology affecting various organs is important. As the students do not have knowledge of pathology, it can create confusion ${ }^{41}$.

\section{Conclusion}

ECE is a useful method for a basic science like Physiology if it is taken up with the traditional teaching method. Better understood, retained and later practically applied, if learned in a clinically significant set-up. ECE 
helps to improve understanding, develop problem solving skills \& increases interaction. Retention of knowledge is better due to integration of basic science and clinical science and development of self directed learning skills. The students get a feeling of being in a medical institute. It helps to develop attitude and professionalism. It is a better learning methodology than traditional teaching alone.

Lastly importance of ECE can be explained in one line by Benjamin Franklin's words of wisdom: “Tell me and I forget, teach me and I may remember, involve me and I learn." 43

\section{Acknowledgement}

I am thankful to Dr Rasmi Vyas, who gave me insight in early clinical exposure and provided resource material for preparing my manuscript. I am thankful to Dr Swapnil for helping me in preparing smart art for this manuscript. I am obelise by Editorial team for providing me opportunity to share my view on ECE.

\section{Reference}

1. Verma M. Early clinical exposure: New paradigm in Medical and Dental Education. Contemp Clin Dent 2016;7:287-8.

2. Medical Professionalism Project. Medical professionalism in the new millennium. Clin Med JRCPL 2002;2:116-8.

3. Irvine $\mathrm{D}$. The performance of doctors: new professionalism. Lancet 1999;353:1174-7.

4. General Medical Council. Tomorrow's doctors. 2nd ed. London: GMC, 2002.

5. Howe A. Professional development in undergraduate medical curricula - the key to the door of a new culture? Med Educ 2002;36:353-9.

6. Gordon J. Fostering students' personal and professional development in medicine: a new framework for PPD. Med Educ 2003;37:341-9.

7. Gordon J, Hazlett C, ten Cate O, Mann K, Kilminster S, Prince K, et al. Strategic planning in medical education: enhancing the learning environment in clinical settings. Med Educ 2000;34:841-50.

8. Dahle LO, Brynhildsen J, Berbohm Fallsberg M, Rundquist I, Hammar M. Pros and cons of vertical integration between clinical medicine and basic science within a problem-based undergraduate medical curriculum: examples and experiences from Linkoping, Sweden. Med Teach 2002;24:280-5.

9. Kachur EK. Observation during early clinical exposurean effective instructional tool or a bore? Med Educ 2003;37:88-9.

10. Bruce TA. Medical education in community sites. Med Educ. 1996;30:81-2.

11. GENERAL MEDICAL COUNCIL. (1993). Tomorrow's Doctor: Recommendations on Undergraduate Medical Education. London: GMC.

12. WORLD FEDERATION FOR MEDICAL EDUCATION. (1998). International standards in medical education: Assessment and accreditation of medical schools' educational programmes. Medical Education, 32, $549-558$

13. HEALTH PROFESSIONS COUNCIL OF SOUTH AFRICA. (1999). Education and Training of Doctors in South Africa. Undergraduate Medical Education and
Training. Guidelines by the Medical and Dental Professional Board. Pretoria: Medical and Dental Professional Board.

14. Basak, O., Yaphe, J., Spiegel, W., Wilm, S., Carelli, F., \& Metsemakers, J. F. (2009). Early clinical exposure in medical curricula across Europe: An overview. The European Journal of General Practice, 15(1), 4-10.

15. Widyanadana, D., Majoor, G., \& Scherpbier, A.(2012). Preclinical students' experiences in early clerkships after skills training partly offered in primary health care centers: A qualitative study from Indonesia. BMC Medical Education, 12(1), 35.

16. Piryani, R. M., Shankar, P. R., Thapa, T. P., Karki, B. M., Kafle, R. K., Khakurel, M. P., \& Bhandary, S. (2013). Introduction of structured physical examination skills to second year undergraduate medical students. F1000 Research, 2, 16. f1000research.2-16.v1

17. Medical Council of India Vision 2015. Available from http://www.mciindia.org/tools/announcement/MCI_bookl et.pdf Accessed on 22nd November 2012.

18. Elizabeth $\mathrm{K}$; Observation during early clinical exposurean effective instructional tool or a bore. Medical Education, 2003, 37(2) 88-9

19. Dornan T, Boshuizen H, King N, Scherpbier A. Experience-based learning: a model linking the processes and outcomes of medical students' workplace learning. Medical Education 2007; 41:84-91

20. Vu, T. N., \& Mensah-Dapaah, J. (2014). Integration of Early Clinical Experience and Population Health in Undergraduate Medical Education. http://corescholar.libraries.wright.edu/mph/141

21. McLean M. Education for Health. 2004, 17 (1):42-52.

22. Dyrbye LN, Harris I, Rohren CH. Early clinical experiences from students' perspectives: A qualitative study of narratives. Academic Medicine, 2007;82(10):979-88.

23. Rashmi Vyas, Solomon Sathish kumar. Recent Trends In Teaching and Learning In Physiology Education Early Clinical Exposure And Integration, International Journal of Basic and Applied Physiology, 2012;1(1).

24. Michalec B. Clinical experiences during preclinical training: The function of modelled behaviour and The evidence of professionalism principles. Int J Med Edu. 2012;3:37-45.

25. Barrows, H.S. and R.M. Tamblyn 1980 Problem-Based Learning. An Approach to Medical Education. New York: Springer Publishing Company.

26. McLean M. Sometimes We Do Get it Right! Early Clinical Contact is a Rewarding Experience. Education for Health 2004, 17(1):42-52.

27. O’Brien-Gonzales A, Blavo C, Barley G, Steinkohl DC, Loeser H. What Did We Learn about Early Clinical Experience? Acad Med 2001, 76 (4):S49.

28. Sathish kumar S, Thomas N, Tharion E, Neelkantan N, Vyas R. Attitude of medical students towards Early Clinical Exposure in learning endocrine physiology. BMC Med Edu 2007,7:30.

29. 7. Vyas R, Jacob M, Faith M, Isaac B, Rabi S, Sathish kumar S, D Selva kumar D, Ganesh A. An effective integrated-learning programme in the first year of the medical course. Natl Med J India 2008, 21:21-6.

30. Sharad kumar Pralhad Sawant, Shaheen Rizvi. ECE AS A NOVEL TEACHING-LEARNING METHOD IN CURRICULUM OF ANATOMY. Int J Anat Res 2015;3(3):1207-11.

31. Morris C. Teaching and learning through active observation. Available from: http://www.faculty.londondeanery.ac.uk/e- 
learning/feedback/files/T-

L_through_active_observation.pdfAccessed on 23rd

November 2012.

32. Kachur EK. Observation during early clinical experience - an effective instructional tool or a bore? Medical Education 2003; 37:88-9.

33. Sandra JL: Multiple-format sessions for teaching endocrine physiology. Adv Physiol Educ 2001, 25:22832.

34. Freeman, J., et al., A longitudinal primary care program in an urban public medical school: Three years of experience. Acad Med, 1995. 70(11 Suppl): p. S64-8.

35. Linder, B.M., A. Saha, and G.F. Heseltine, Teaching clinical skills to new medical students: the Oman experience. Med Educ, 1992. 26: p.282-4.

36. Thomas, E.J., J.P. Hafler, and B. Woo, The patient's experience of being interviewed by first-year medical students. Med Teach, 1999. 21:p. 311-4.

37. Cook, D. A. (2010). Twelve tips for evaluating educational programs. Medical Teacher, 32(4),296-301.

38. Vernon DTA; Attitudes and opinions of faculty tutors about problem - based learning. Acad Med.,1995; 70(3):216-23.

39. Satheesha N, Komattil R, Nagabhooshana S, Kuvady LB; Teaching anatomy in a problem -based learning (PBL) curriculum. Neuroanatomy, 2006;5:2-3.

40. Tayade MC, Bhimani N, Kulkarni NB, Dandekar KN; The impact of early clinical exposure on first M.B.B.S students. International J. of Healthcare and Biomedical Research, 2014; 2(4):176-81.

41. Baheti SN, Maheshgauri D; Early Clinical Microexposure (Ecmix) (A Path From Early

42. Clinical Micro Exposure to Early Clinical Macro Exposure (Ecmax), Global Journal For Research Analysis, 2015;4(3):1-2.

43. http://www.goodreads.com/quotes/21262-tell-me-and-iforget-teach-me-and-i-may 